\title{
In-situ investigation of stress-induced martensitic transformation in Ti-Nb binary alloys with low Young's modulus
}

\author{
L.L. Chang ${ }^{1 *}$, Y.D. $\mathrm{Wang}^{2}$, Y. Ren $^{3}$
}

${ }^{1}$ School of Materials Science and Engineering, Shandong University, Jinan, 250061, China

${ }^{2}$ State Key Laboratory for Advanced Metals and Materials (SKLAMM) and the Collaborative Innovation Center of Steel Technology (CICST), University of Science and Technology Beijing, Beijing 10081, China

${ }^{3}$ X-Ray Science Division, Argonne National Laboratory, Argonne, IL 60439, USA

\begin{abstract}
Microstructure evolution, mechanical behaviors of cold rolled Ti-Nb alloys with different $\mathrm{Nb}$ contents subjected to different heat treatments were investigated. Optical microstructure and phase compositions of Ti-Nb alloys were characterized using optical microscopy and X-ray diffractometre, while mechanical behaviors of Ti-Nb alloys were examined by using tension tests. Stress-induced martensitic transformation in a Ti-30at.\% $\mathrm{Nb}$ binary alloy was in-situ explored by synchrotron-based high-energy X-ray diffraction (HE-XRD). The results obtained suggested that mechanical behavior of Ti-Nb alloys, especially Young's modulus was directly dependent on chemical compositions and heat treatment process. According to the results of HE-XRD, $\alpha "-\mathrm{V} 1$ martensite generated prior to the formation of $\alpha "-\mathrm{V} 2$ during loading and a partial reversible transformation from $\alpha^{\prime \prime}-\mathrm{V} 1$ to $\beta$ phase was detected while $\alpha "-\mathrm{V} 2$ tranformed to $\beta$ completely during unloading.
\end{abstract}

Keywords: Ti-Nb alloys; Microstructure; Mechanical properties; Martensite transformation

\footnotetext{
* Corresponding author. Fax: +8653188392157

Email address: lilichang@sdu.edu.cn

Corresponding author at: School of Materials Science and Engineering, Shandong University, 17923 Lixia District, Jinan, 250061, China 


\section{Introduction}

Ti-based alloys have attracted much attention due to their high corrosion resistance, good compatibility, low Young's modulus $[1,2]$. Recently, $\beta$-type Ti-Nb based alloys consisting of non-toxic elements have attracted considerable interest as a promising biomaterial. Those alloys exhibit a martensitic transformation from $\beta$ (disordered bcc) to hexagonal martensite $\left(\alpha^{\prime}\right)$ or orthorhombic martensite $\left(\alpha^{\prime \prime}\right)$, which depends mainly on the alloy composition and materials processing [3-5]. Previous sstudies have shown that acicular $\alpha^{\prime \prime}$ may form either in isothermal conditions or under tensile tests [6-9]. Reports indicated that martensite formation becomes possible below Ms by supplying an extra amount of energy by mechanical means, which is referred to as stress-induced martensite (SIM) [6]. SIM formation may lead to concomitant improvements in strength and ductility, as has been demonstrated in steel technology [6]. On the other hand, a low Young's modulus of approximately $40 \mathrm{GPa}$ has been observed to occur in an unstable $\beta$ Ti alloy polycrystal undergoing stress-induced $\alpha^{\prime \prime}$ martensitic transformation during cold rolling [8]. Recently, the low modulus and superelasticity of metastable $\beta$ titanium alloys was elucidated by a continuous phase transformation from $\beta$ to $\alpha^{\prime \prime}$ during loading [10]. Those aforementioned results have indicated that the deformation mechanisms in the Ti-Nb system alloys are quite complex, which are closely related not only to the stability of the $\beta$ phase but also to the detailed scenario of deformation process. Moreover, mechanical behaviors of $\mathrm{Ti}-\mathrm{Nb}$ alloys are directly correlated to evolution of microstructure during deformation. For the sake of tailoring Ti-Nb alloys for biomaterial application, an in-depth understanding of the microstructure evolution, phase transformation behavior, mechanical properties and relationship between them is required. The aim of this paper is to investigate the relationship between microstructure and mechanical properties of $\mathrm{Ti}-\mathrm{Nb}$ alloys. Stress-induced $\alpha^{\prime \prime}$ martensite transformation was characterized by using in-situ high-energy X-ray diffraction (HE-XRD). The evolution of lattice strain and phase transformation kinetics vs. applied stress in the Ti-30at.\% $\mathrm{Nb}$ (noted as Ti-30Nb) alloy were in-situ traced during tensile loading and unloading. 


\section{Experiment}

The Ti-20at.\% $\mathrm{Nb}(\mathrm{Ti}-20 \mathrm{Nb})$ and Ti-30at.\% $\mathrm{Nb}(\mathrm{Ti}-30 \mathrm{Nb})$ ingots were melted in an arc-melting furnace under argon atmosphere. Ingots were melted six times to ensure chemical homogeneity. The as-cast alloys were sealed in a vacuum in a quartz tube and homogenized at $1000^{\circ} \mathrm{C}$ for $3.6 \mathrm{ks}$ followed by furnace cooling. Cold-rolling was conducted at room temperature with a reduction of $90 \%$ in thickness and the final thickness of Ti-Nb sheets was about $1 \mathrm{~mm}$. Specimens for optical microstructure observation, X-ray diffraction (XRD) and tension were cut using an electro-discharge machine. The specimens were cleaned with ethanol and encapsulated in quartz under a 25 Torr partial pressure of high-purity Ar to avoid oxidation during solution treatment. Solution heat treatments of Ti-Nb alloys were conducted at $750^{\circ} \mathrm{C}, 850^{\circ} \mathrm{C}$ and $950^{\circ} \mathrm{C}$ for $3.6 \mathrm{ks}$, respectively and specimens were quenched into water by breaking the quartz tubes. Optical microstructure of $\mathrm{Ti}-\mathrm{Nb}$ alloys was revealed by using an etchant of $\mathrm{HF}(5 \mathrm{vol} . \%)+\mathrm{HNO}_{3}(5 \mathrm{vol})+$. water(bal.). XRD measurements were conducted at room temperature using a Rigaku D/MAX diffractor with $\mathrm{Cu}-\mathrm{K} \alpha$ radiation ( $\lambda=1.5406 \AA$ ) operating at $40 \mathrm{kV}$ and $30 \mathrm{~mA}$. Tensile tests were carried out at a strain rate of $1.0 \times 10^{-3} \mathrm{~s}^{-1}$ at room temperature. The gauge length of specimens was $20 \mathrm{~mm}$, and triplicate tests along rolling direction (RD) were conducted. The fracture morphology was observed using scanning electron microscopy (SEM) Quanta FEG 250 operated at $15 \mathrm{kV}$.

In-situ synchrotron-based HEXRD experiments were performed for studying the mechanical behavior of the Ti-Nb alloy, using the beam-line 11-ID-C at the Advanced Photon Source (APS) at Argonne National Laboratory. An intense monochromatic X-ray beam with the energy of $115 \mathrm{keV}$ (wavelength of $0.10801 \AA$ ) and a beam size of $400 \times 400 \mu \mathrm{m}^{2}$ was used to map the lattice strain distributions of the specimens under the tensile loading mode. At different loading levels, the diffraction patterns were recorded on a two-dimensional (2D) detector, which was placed at about $2.1 \mathrm{~m}$ behind the sample. The $\mathrm{CeO}_{2}$ powders were attached to the surface of the measured specimen for calibrating the accurate distance between the 
specimen and the geometry position of 2D detector during deformation. During the in-situ experiments, the $\mathrm{CeO}_{2}$ powders were removed from the sample for obtaining clear diffraction patterns. The Bragg angle $\theta_{h k l}$ of the $h k l$ plane was determined by fitting the individual single peak or overlapped peaks in the diffraction spectra with General Structure Analysis System (GSAS) software.

\section{Results and discussion}

\subsection{Microstructure evolution}

Fig. 1 shows optical microstructures of Ti-Nb binary alloys obtained by quenching into water from different solution treatment temperatures. As seen in Fig. 1(a-c), $\alpha^{\prime \prime}$ martensite plates nucleated and distributed homogeneously inside $\beta$ grains of Ti-20Nb alloys. The average $\beta$ grain size of Ti-20Nb alloys solution treated at $750^{\circ} \mathrm{C}, 850^{\circ} \mathrm{C}$ and $950^{\circ} \mathrm{C}$ was determined to be about $55 \mu \mathrm{m}, 114 \mu \mathrm{m}$ and $162 \mu \mathrm{m}$, respectively. Unlike $\left(\beta+\alpha^{\prime \prime}\right)$ microstructure of $\mathrm{Ti}-20 \mathrm{Nb}$, the microstructure of solution treated $\mathrm{Ti}-30 \mathrm{Nb}$ alloys showed single $\beta$ phase grain structure and the average $\beta$ grain size of Ti-30Nb after solution treatment at $750^{\circ} \mathrm{C}, 850^{\circ} \mathrm{C}$ and $950^{\circ} \mathrm{C}$ was $\sim 51 \mu \mathrm{m}, \sim 60 \mu \mathrm{m}$ and $\sim 65 \mu \mathrm{m}$, respectively. The results indicated that for both $\mathrm{Ti}-20 \mathrm{Nb}$ and $\mathrm{Ti}-30 \mathrm{Nb}$ specimens, the grain size of $\beta$ increased with the increasing solution treatment temperature. The stability of bcc $\beta$ phase in Ti-M alloys ( $\mathrm{M}=$ trainstition element) can be understood from two aspects [11]: (1) the formation energies of compositions, i.e. decrease in formation energy indicates increase in stability of the phase; (2) the ratio of valence electrons and number of atoms (e/a), $\beta$ phase in Ti-M alloys is stablized at the e/a ratio is 4.2 or more. Karre et al. calculated binary Ti-Nb systms using first-principles calculations with density-functional framework, the theoretical results suggest that the Ti-Nb alloy system have stable bcc $(\beta)$ phase for $\mathrm{Nb}$ content 22 at.\% and higher [11]. However, according to Bönisch et al., $\beta$ phase was detected in Ti-29wt.\% Nb (Ti-18at.\% Nb) alloys solution treated at $670 \mathrm{~K}+\mathrm{WQ}$ (water quenched), $818 \mathrm{~K}+\mathrm{WQ}, 1420 \mathrm{~K}+\mathrm{WQ}$ [12], which indicated the stability of $\beta$ phase was significantly 
influenced by heat treatment process. For our case, $\alpha^{\prime \prime}$ and $\beta$ phases were both observed in the optical microstructure of cold and solution treated Ti-20Nb alloys, the existence of $\beta$ was also confirmed by the XRD results, as seen in Fig.2 (a). Further investigation of optical microstrucutre indicated that the average $\beta$ grain size of Ti-30Nb was slightly influenced by solution treatment temperature as Ti-20Nb samples do. According to previous experimental work, solutes have great influence on grain boundary mobility and hence on the growth rate of recrystallizing grains [12]. Usually, the solute is attracted to the grain boundary and solute segregation occurs, the solute atoms can induce a "solute drag" force on the moving boundaryto hinder recrystallization. Therefore, when the $\mathrm{Nb}$ addition was increased, the resistance for grain growth was increased, which resulted in insensitivity of grain size to solution temperature, as shown in Fig. 1.

XRD patterns of Ti-Nb alloys in cold rolled and solution treated states were shown in Fig. 2 and lattice parameters calculated from XRD results were summarized in Table 1. XRD diffraction peaks of cold rolled and solution treated $\mathrm{Ti}-20 \mathrm{Nb}$ alloys were indexed as $\beta$ and $\alpha^{\prime \prime}$ phases, indicating that the martensitic transformation finish temperature $\left(\mathrm{M}_{\mathrm{f}}\right)$ of Ti-20Nb alloys was lower than the room temperature (RT), while the martensitic transformation start temperature $\left(\mathrm{M}_{\mathrm{s}}\right)$ was higher than RT. According to the XRD results, the lattice parameter of $\beta$ in cold rolled Ti-20Nb alloy was determined to be $a_{\beta}=3.2714 \AA$, while those of the $\alpha^{\prime \prime}$ phase were determined to be $\mathrm{a}_{\alpha^{\prime \prime}}=3.0805 \AA, \mathrm{b}_{\alpha^{\prime \prime}}=4.8300 \AA$ and $\mathrm{c}_{\alpha^{\prime \prime}}=4.7256 \AA$. For cold rolled and solution treated $\mathrm{Ti}-30 \mathrm{Nb}$ alloys, all diffraction peaks were indexed as $\beta$ phase and its lattice parameter decreased slightly with increasing the solution temperature. Previous studies have revealed that the lattice of constants of phases in $\mathrm{Ti}-\mathrm{Nb}$ alloys strongly depend on the $\mathrm{Nb}$ content of the alloys. The $\mathrm{Nb}$ content dependence of the $\beta$ and $\alpha^{\prime \prime}$ orthorhombic martensite in Ti-Nb alloys was reported by Kim et al. [13]. According to their results, the lattice constant of the $\beta$ phase slightly increases by $0.013 \times 10^{-3} \mathrm{~nm} / 1$ at. $\% \mathrm{Nb}$ in the Ti-(22-35)at.\% $\mathrm{Nb}$ alloys and the lattice constant of $\beta$ phase in cold-rolled Ti-22at.\% $\mathrm{Nb}$ and Ti-30at.\% $\mathrm{Nb}$ was determined to be $3.2861 \AA$ and $3.2872 \AA$, respectively. In the present study, the lattice constant of $\beta$ 
phase in cold-rolled Ti-20Nb was 3.2714 $\AA$, and it increased to be $3.2901 \AA$ in cold-rolled Ti-30Nb alloys by $0.6 \%$ increment. On the other hand, the lattice constant of $\beta$ phase in cold rolled and solution treated Ti-Nb alloys was in the range of 3.2901 3.2838 $\AA$, which agreed well with Kim's results [14]. Besides alloy compositions, the type and lattice constants of phases are also extremely dependent on heat treatment process and the thermal stability. Phase evolution during heat treatment of martensitic Ti-Nb alloys was investigated by a number of authors $[12,15-17]$. Our work indicated that the lattice parameter of $\beta$ in Ti-20Nb alloys decreased by $2.05 \times 10^{-6} \AA{ }^{\circ} \mathrm{C}$ with the increasing solution treatment temperature, as shown in Table 1. For the case of Ti-30Nb alloys, the value was determined to be $1.855 \times 10^{-5} \AA{ }^{\circ} \mathrm{C}$, which is almost ten times of the value of Ti-20Nb alloys. Two main factors could have possibly caused the change of lattice constants of phases during heating: (1) atom dissolving and (2) misfit accomodation [18]. As discussed above, $\beta$ converted into $\alpha^{\prime \prime}$ martensite occurred during quenching of Ti- $20 \mathrm{Nb}$ alloys, while the Ti-30Nb alloys maintained a single $\beta$ phase microstructure during heating and quenching. The misfit between lattice constants of $\beta$ and $\alpha^{\prime \prime}$ would obviously influence the variation of the lattice constant of $\beta$ phase. Furthermore, the martensite transformation in Ti-20Nb alloys during water quench devided the $\beta$ grains and induced "refining" of $\beta$ grains actually. Therefore, the lattice parameter evolution of $\beta$ was restricted by $\alpha$ " martensite transformation via misfitting and refining, which resulted in insensitivity of $\beta$ grain size to the solution temperature.

\subsection{Mechanical properties}

Stress-strain curves for Ti-20Nb and Ti-30Nb alloys in cold rolled state and solution treated states were shown in Fig. 3. The values of Young's modulus $(\mathrm{E})$, yield stress $\left(\sigma_{0.2}\right)$, ultimate tensile stress $\left(\sigma_{\mathrm{b}}\right)$ and elongation-to-failure $(\delta)$ for samples of Ti-20Nb and Ti-30Nb alloys were determined and listed in Table 2. According to the results, the cold rolled samples showed largest Young's moduli, highest YS and UTS, but lowest elongation, which is the result of the work hardening. After solution treatment at different 
temperatures, the Young's modulus, YS and UTS of Ti-Nb alloys decreased, while the elongation increased significantly as a result of heat treatment. It is interesting to find that strengths of Ti-20Nb alloys exhibited abnormal Hall-Petch relationship: YS and UTS increases as the $\beta$ grain size increased. Based on the analysis of optical microstructures of Ti-20Nb samples, the amount of $\alpha^{\prime \prime}$ martensite increased significantly with the increasing temeperature, therefore, the spacing of $\alpha^{\prime \prime}$ phases decrease largely, which induced hardening of Ti-Nb alloys offsetting the softing of larger $\beta$ grain size, resulting in high strength Ti-20Nb alloys with large grain size. The Young's modulus of Ti-20Nb alloys solution treated at $850{ }^{\circ} \mathrm{C}$ was slightly larger than that of Ti-30Nb alloys solution treated at $850{ }^{\circ} \mathrm{C}$, while the UTS was much larger than those of Ti-30Nb alloys in solution treated conditions. It should be noted that the elongation of $\mathrm{Ti}-20 \mathrm{Nb}$ alloys after solution treated at $850{ }^{\circ} \mathrm{C}$ was the largest among all the $\mathrm{Ti}-\mathrm{Nb}$ samples.

The elastic modulus of materials is one of the intrinsic natures of materials, determined by the bonding force among atoms. The Young's mudulus of Ti-Nb alloys was reported to be profoundly influenced by the $\mathrm{Nb}$ content and the presence of phases. According to previous report from Ozaki et al., a minimum in Young's modulus was observed at the composition of Ti-26at.\% $\mathrm{Nb}$ (Ti-40\% $\mathrm{Nb}$ in mass) quenched from the $\beta$ region [19]. Lee et al. reported a strong dependence of $E$ on the chemical composition and the minimum of E was observed near a compostion of Ti-35wt.\% $\mathrm{Nb}$ [20]. For various phases of Ti alloys, in general, $\mathrm{E}_{\beta}<\mathrm{E}_{\alpha^{\prime \prime}}$ $<\mathrm{E}_{\omega}$ [21]. Sun et al. calculated the phase stability, electronic structure and elastic constants of $\beta, \alpha^{\prime \prime}$ and $\omega$ metastable phases in Ti-25at.\% Nb alloys by first-principles calculations [22]. Their results indicated that in the Ti-25 at. $\% \mathrm{Nb}$ alloy $\omega$ phase has the highest Young's modulus among $\beta, \alpha^{\prime \prime}$ and $\omega$ metastable phases, while $\beta$ has lowest Young's modulus. In the present study, combing with the XRD results, it can be considered that $\mathrm{Ti}-30 \mathrm{Nb}$ alloys have lower modulus due to the microstructure of a single $\beta$ phase (45 67 GPa), and $\alpha^{\prime \prime}$ phase contributes to the higher modulus of the Ti-20at.\%Nb alloys (49 118 GPa). Further investigation of strain-stress curves of Ti-Nb alloys indicated that the work hardening in Ti-20Nb alloys was 
much larger than that in Ti-30Nb alloys. The reason is that $\alpha^{\prime \prime}$ phase in Ti-20Nb alloys divided larger $\beta$ grains and thus reducing the effective slip distance of dislocation and thereby raised the work hardening rate via Hall-Petch equation. It is interested to note that a plateau was observed in tensile curves of both Ti-20Nb and Ti-30Nb samples solution treated at $750{ }^{\circ} \mathrm{C}$. The plateau due to double yielding was considered to be related to stress-induced $\alpha^{\prime \prime}$ martensite transformation [23].

As discussed above, the $\mathrm{Ti}-\mathrm{Nb}$ alloys with different $\mathrm{Nb}$ contents after solution treatment at $850{ }^{\circ} \mathrm{C}$ showed satisfactory combined tensile properties. For further investigation, SEM observation of fracture surfaces of Ti-Nb alloys in solution condition was conducted and tensile fractographic structures of $\mathrm{Ti}-\mathrm{Nb}$ alloys solution treated at $850{ }^{\circ} \mathrm{C}$ were shown in Fig. 4. The fracture surface of Ti-20Nb solution treated at $850{ }^{\circ} \mathrm{C}$ exhibited a dimpled morphology and cleavage fracture surface, while the fractographic structure of Ti-30Nb solution treated at $850{ }^{\circ} \mathrm{C}$ was shown to be a finely dimpled morphology due to the single $\beta$ phase microstructure with a samll average grain size. By way of contrast, the fracture surface of Ti-20Nb has a coarse dimpled morphology, which was related to the $\left(\beta+\alpha^{\prime \prime}\right)$ duplex phase microstructure with relatively large $\beta$ grains.

\subsection{Scenario of $\beta$ to $\alpha "$ transformation in Ti-30Nb alloys}

A direct experimental observation of the stress-induced martensite transformation can be conducted by using in-situ HE-XRD technique, favoring for understanding lower Young's modulus in Ti-Nb alloys. Fig. 5 shows the $2 \mathrm{D}$ diffraction patterns together with the integrated one-dimensional (1D) patterns of the Ti-30Nb alloy at the stress of $0 \mathrm{MPa}$ (before loading), $498 \mathrm{MPa}$ (at the maximum stress) and $0 \mathrm{MPa}$ (after unloading) along loading direction (LD). The diffraction patterns at $0 \mathrm{MPa}$ (before loading) were composed of intense rings that can be indexed as the body-centered-cubic (bcc) structure of beta phase $(\beta)$. No peak belong to any other metastable phases (such as $\omega, \alpha^{\prime \prime}, \alpha^{\prime}$ ) was detected, which indicates that after solution treatment at

$1123 \mathrm{~K}$ for $1 \mathrm{~h}$, Ti-30Nb alloy was completely composed of a single $\beta$ phase. When the applied stress was 
increased to $498 \mathrm{MPa}(\varepsilon=8.7 \%),\{020\}_{\alpha^{\prime}}$ and $\{021\}_{\alpha^{\prime}}$ diffraction peaks of martensite $\alpha$ " were detected, as seen in Fig. 5(b) which indicated that stress-induced $\alpha "$ martensitic transformation occurred during the tensile loading. Fig. 5(c) showed peaks of $\alpha "$ remained in the diffraction patterns after the applied stress was removed. Comparing to the intensities of peaks at $498 \mathrm{MPa}$, the intensities of $\{020\}_{\alpha \text { " }}$ and $\{021\}_{\alpha \text { " }}$ diffraction peaks of samples unloaded decreased slightly, indicating that a partial reverse martensitic transformation from $\beta$ to $\alpha$ " indeed took place during unloading.

Besides the diffraction peaks belong to the deformation-induced $\alpha$ " phase, it is interesting to note that a diffraction peak near $\{110\}_{\beta}$ peak was also detected during the in-situ loading and unloading, as shown in Fig. 6(a). For clarity, diffraction profiles near $\{110\}_{\beta}$ peak at $0 \mathrm{MPa}$ (before loading), $498 \mathrm{MPa}$ (at the maximum stress) and (d) $0 \mathrm{MPa}$ (after unloading) are highlighted in Fig. 6(b-d), and the peak near $\{110\}_{\beta}$ peak was indexed as $\{002\}_{\alpha "}$, belong to a variant of $\alpha "$ martensite. Further investigation indicated that $\{002\}_{\alpha "}$ diffraction peak completely disappeared after the applied stress was removed (Fig. 6d), which suggests a completely reversible transformation during unloading process. As discussed above, two variants of $\alpha "$ martensite was detected during in-situ HE-XRD investigation. For easy discussion, the $\alpha "$ martensite variant with the normal direction of $\{020\}_{\alpha "}$ along the loading direction was noted as $\alpha$ " -V1, while those $\alpha^{\prime \prime}$ martensite variants with orientation of [002] $\alpha^{\prime \prime}$ parallel to the loading direction were maked as $\alpha "$-V2.

In-situ HE-XRD experiments show the response of lattice strain vs. applied stress for $\alpha$ " variants, as shown in Fig. 7(a). As seen in Fig. 7(a), in the beginning of loading (50-350 MPa), the lattice strain of $\{020\}_{\alpha "}$ did not change obviously. The applied stress was accommodated mostly by the nucleation and activation of $\alpha^{\prime}$ phase. When the applied stress was increased from 350 to $460 \mathrm{MPa}$, the lattice strain of $\{020\}_{\alpha "}$ increased linearly with the applied stress due to the elastic deformation of $\alpha$ " phase. When the

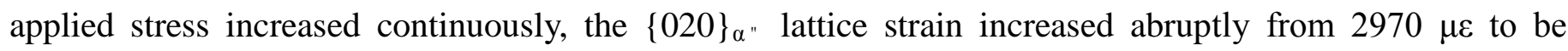


$11570 \mu \varepsilon$. The abrupt increment in the lattice strain was considered as the result of phase transformation from $\beta$ phase to $\alpha$ " -V2 variant. During unloading process, the evolution of $\{020\}_{\alpha}$ lattice strain was marked as two stages, the first stage (498-460 MPa) was related to the reversible transformation from the $\alpha^{\prime \prime}-\mathrm{V} 1$ or $\alpha^{n}$-V2 martensite to $\beta$ phase, while during the second stage (460-0 MPa) the lattice strain decreased linearly with the applied stress, which was attributed to only elastic deformation of $\alpha$ " martensite.

The phase transformation kinetics vs. applied stress, i.e. the evolution of volume fraction for $\beta, \alpha^{\prime \prime}$, was shown in Fig.7 (b). The $\alpha$ " -V1 martensite was first detected at the applied stress of $~ 98 \mathrm{MPa}$, and then the volume fraction of $\alpha$ " increases with the increasing applied stress during tensile loading. When the applied stress was increased to $498 \mathrm{MPa}$, the volume fraction of the $\alpha$ " -V1 was determined to be $20 \%$. The volume fraction of $\alpha "-\mathrm{V} 1$ decreased significantly with the decreasing of the macrostress. After the sample was unloaded completely, $\sim 10 \%$ of $\alpha "$-V1 phase remained. For the case of $\alpha$ " -V2 variant, the volume fraction jumped from 0 to $\sim 10.6 \%$ at the applied stress of $460 \mathrm{MPa}$. After that the value of the volume fraction of $\alpha$ " -V2 sustained until the applied stress was decreased to be $\sim 262 \mathrm{MPa}$. When the macrostress was samller than $262 \mathrm{MPa}$, the volume fraction of $\alpha$ " -V2 was abruptly decreased to be $\sim 0$. According to the aforementioned results and discussion,the evolution of the volume fractions for $\beta, \alpha^{\prime \prime}$ variants at different stress states indicated that behavior of $\alpha "$-V1 variant was entirely different with $\alpha$ " - V2. $\alpha^{\prime \prime}-$ V1 martensite transformation developed gradually as the applied stress was increased step by step, while $\alpha$ " -V2 variant seemed to form suddenly. In addition, the volume fraction of $\alpha^{\prime \prime}-\mathrm{V} 1$ martensite decreased with decreasing the applied stress progressively, while the volume fraction of $\alpha$ " -V2 remained a steady value of $\sim 10 \%$ during the beginning of unloading and jumped to $0 \%$ at $262 \mathrm{MPa}$. Therefore, a seqence from $\beta$ to $\alpha "-\mathrm{V} 1$ and from $\beta$ to $\alpha "-\mathrm{V} 2$ martensite transformation in the binary alloy was evidenced during tensile loading and unloading. Different phase transformation kinetics was revealed for both kinds of martensite variant. The $\alpha$ " -V1 martensite is generated prior to the formation of $\alpha$ " -V2 
during loading. A partial reversible transformation from $\alpha^{"}-\mathrm{V} 1$ to $\beta$ phase occurred firstly while a completely reversible transformation from $\alpha$ " -V2 to $\beta$ took place abruptly under high stress level .

\section{Conclusions}

Ti-Nb alloys with different $\mathrm{Nb}$ contents were fabricated by argon arc melting followed by cold rolling and solution treatments. Optical microstructure and phase composition of $\mathrm{Ti}-\mathrm{Nb}$ alloys were characterized by optical microscopy, X-ray analysis, and the effect of microstructure on mechanical properties, especially on Young's modulus was discussed. In-situ HE-XRD investigation was used to characterize stress-induced transformation during deformation.The main results are concluded as follows:

1. Cold rolled and solution treated Ti-20Nb alloys were composed of $\beta$ and $\alpha^{\prime \prime}$ phases, while cold rolled and solution treated Ti-30Nb alloys were composed of a single $\beta$ phase. The average grain size of $\beta$ phase in Ti-20Nb alloys increased significantly with the solution temperature, while Ti-30Nb samples exhibited a trivial dependence of grain size on the solid solution temperature.

2. Young's moduli of Ti-30Nb alloys were in the range of $45 \sim 67 \mathrm{GPa}$, which is much lower than those of Ti-20Nb alloys (49 118 GPa). Plateaus due to martensite transformation were observed in tensile curves of Ti-30Nb samples solution treated at $750{ }^{\circ} \mathrm{C}$. The Ti-Nb alloys with different $\mathrm{Nb}$ contents solution treated at $850{ }^{\circ} \mathrm{C}$ showed lower modulus combined with higher strength.

3. A seqence from $\beta$ to $\alpha "-\mathrm{V} 1$ and from $\beta$ to $\alpha "-\mathrm{V} 2$ martensite transformation in the binary alloy was evidenced during tensile deformation. $\alpha "$ "V1 martensite generated prior to the formation of $\alpha$ " -V2 during tensile loading. A partial reversible transformation from $\alpha "-\mathrm{V} 1$ to $\beta$ phase was detected while $\alpha "-\mathrm{V} 2$ tranformed to $\beta$ completely during tensile unloading. 


\section{Acknowledgement}

The work was supported by the National Basic Research Program of China (973 Program) under Contract

No. 2012CB619405, the Promotive Research Fund for Excellent Young and Middle-aged Scientists of

Shandong Province (No. BS2013CL034), Independent Innovation Foundation of Shandong University

(GN2013001), the National Natural Science Foundation of China (Grant No. 51401115), the Fundamental

Research Funds for the Central Universities (Grant No. 06111020), and the fundamental research fund by

State Key Laboratory for Advanced Metals and Materials (Grant No. 2014Z-01). Use of the Advanced

Photon Source was supported by the U. S. Department of Energy, Office of Science, Office of Basic Energy

Sciences, under Contract No. DE-AC02-06CH11357.

\section{References}

[1] I.V. Okulov, U. Kühn, J. Romberg, I.V. Soldatov, J. Freudenberger, L. Schultz, A. Eschke, C.G. Oertel, W. Skrotzki, J. Eckert, Materials \& Design, 62 (2014) 14-20.

[2] M. Wen, C. Wen, P. Hodgson, Y. Li, Materials \& Design, 56 (2014) 629-634.

[3] E. Sukedai, Y. Kitano, A. Ohnishi, Micron, 28 (1997) 269-277.

[4] Y. Ohmori, T. Ogo, K. Nakai, S. Kobayashi, Mater. Sci. Eng. A, 312 (2001) 182-188.

[5] M. Tahara, T. Kanaya, H.Y. Kim, T. Inamura, H. Hosoda, S. Miyazaki, Acta Mater., 80 (2014) 317-326.

[6] S. Neelakantan, E.I. Galindo-Nava, D. San Martin, J. Chao, P.E.J. Rivera-Díaz-del-Castillo, Materials Science and Engineering: A, 590 (2014) 140-146.

[7] C. Li, J. Chen, Y.J. Ren, W. Li, J.J. He, J.H. Chen, J. Alloy Compd., 641 (2015) 192-200.

[8] S. Hanada, N. Masahashi, T.K. Jung, Materials Science and Engineering: A, 588 (2013) 403-410.

[9] R. Casati, M. Vedani, A. Tuissi, Scripta Mater., 80 (2014) 13-16.

[10] T. Maeshima, S. Ushimaru, K. Yamauchi, M. Nishida, Mater. Sci. Eng. A, 438-440 (2006) 844-847.

[11] R. Karre, M.K. Niranjan, S.R. Dey, Materials Science and Engineering: C, 50 (2015) 52-58.

[12] M. Bönisch, M. Calin, T. Waitz, A. Panigrahi, M. Zehetbauer, A. Gebert, W. Skrotzki, J. Eckert, Sci. Technol. Adv. Mater., 14 (2013) 055004.

[13] H.Y. Kim, Y. Ikehara, J.I. Kim, H. Hosoda, S. Miyazaki, Acta Mater., 54 (2006) 2419-2429.

[14] H. Ikehata, N. Nagasako, T. Furuta, A. Fukumoto, K. Miwa, T. Saito, Phys. Rev. B, 70 (2004) 174113.

[15] Y.-L. Zhou, D.-M. Luo, Mater. Charact., 62 (2011) 931-937.

[16] Z. Zhou, M. Lai, B. Tang, H. Kou, H. Chang, Z. Zhu, J. Li, L. Zhou, Mater. Sci. Eng. A, 527 (2010) 5100-5104.

[17] Z. He, M. Liu, Mater. Sci. Eng. B, 177 (2012) 986-991.

[18] M.J. Starink, V.M.F. Abeels, P. van Mourik, Mater. Sci. Eng. A, 163 (1993) 115-125.

[19] T. Ozaki, H. Matsumoto, S. Watanabe, S. Hanada, Mater. Trans., 45 (2004) 2776-2779.

[20] C.M. Lee, C.P. Ju, C. Lin, Joural of Oral Rehabiliation, 29 (2002) 314-322. 
[21] A. Panigrahi, M. Bönisch, T. Waitz, E. Schafler, M. Calin, J. Eckert, W. Skrotzki, M. Zehetbauer, J. Alloy Compd., 628 (2015) 434-441.

[22] J. Sun, Q. Yao, H. Xing, W.Y. Guo, J. Phys.: Condens. Matter 19 (2007 ) 1-8.

[23] M. Tahara, H.Y. Kim, T. Inamura, H. Hosoda, S. Miyazaki, Acta Mater., 59 (2011) 6208-6218. 

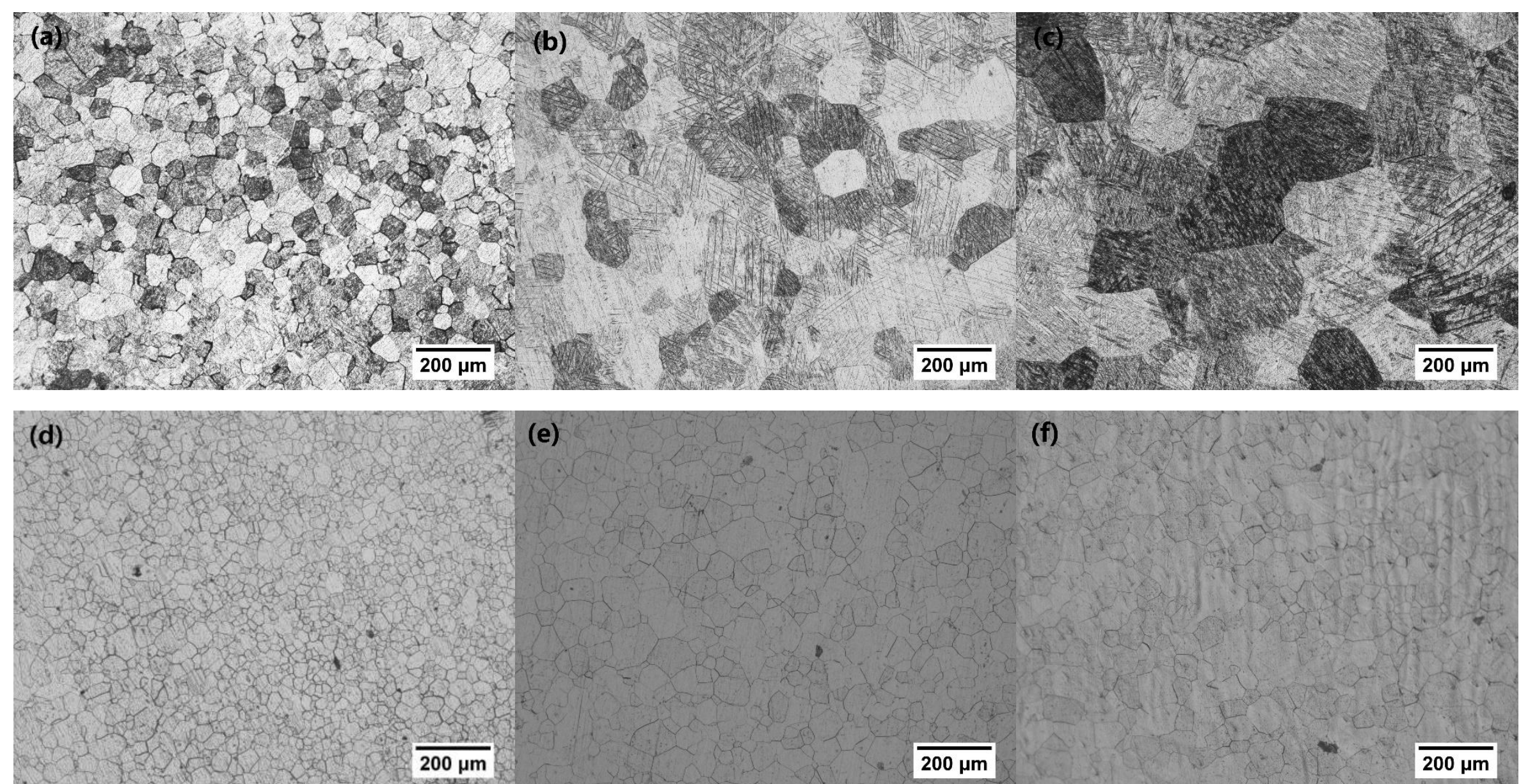

(e)

(f)

Fig. 1 Optical microstructures of Ti-Nb alloys in solution heat treatment: (a)Ti-20Nb-750 ${ }^{\circ} \mathrm{C}$; (b)Ti-20Nb-850 ${ }^{\circ} \mathrm{C}$; (c) Ti-20Nb-950 ${ }^{\circ} \mathrm{C}$; (d)Ti-30Nb-750 ${ }^{\circ} \mathrm{C}$; (e)Ti- $30 \mathrm{Nb}-850^{\circ} \mathrm{C}$; (f) $\mathrm{Ti}-30 \mathrm{Nb}-950^{\circ} \mathrm{C}$ 

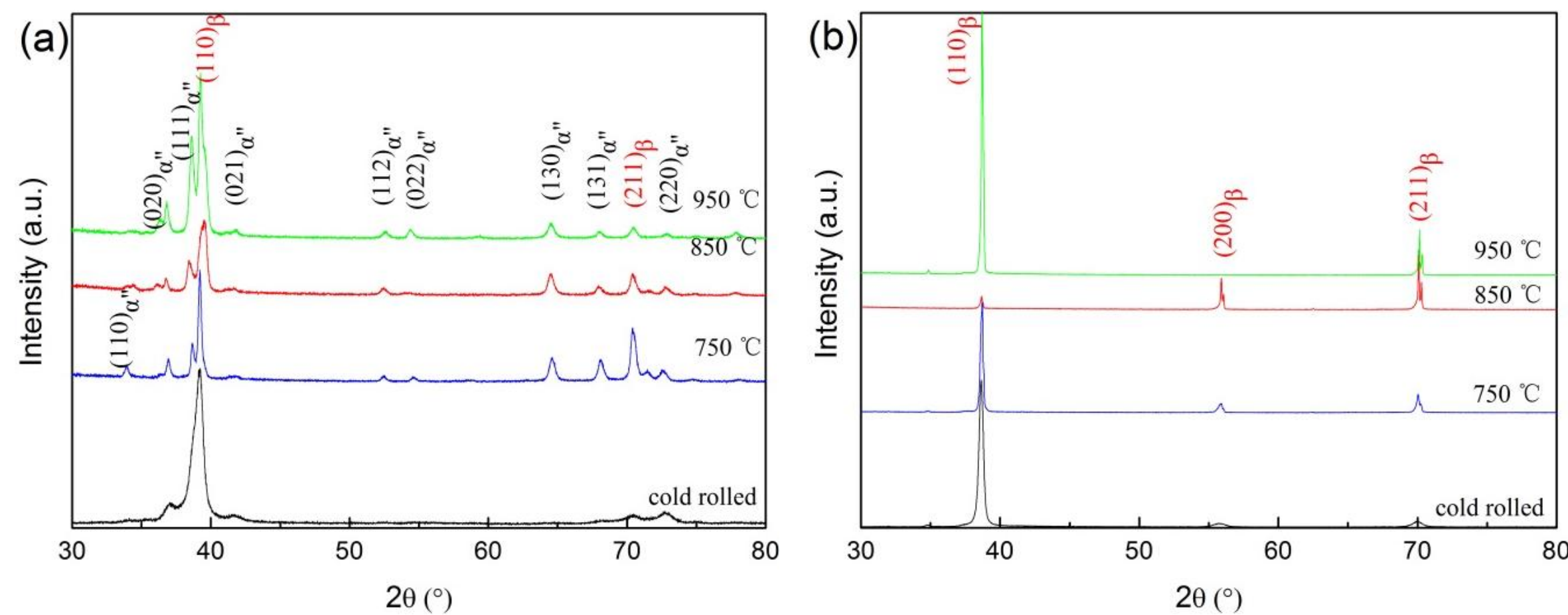

Fig. 2 XRD patterns of Ti-Nb alloys: (a) Ti-20Nb; (b) Ti-30Nb 

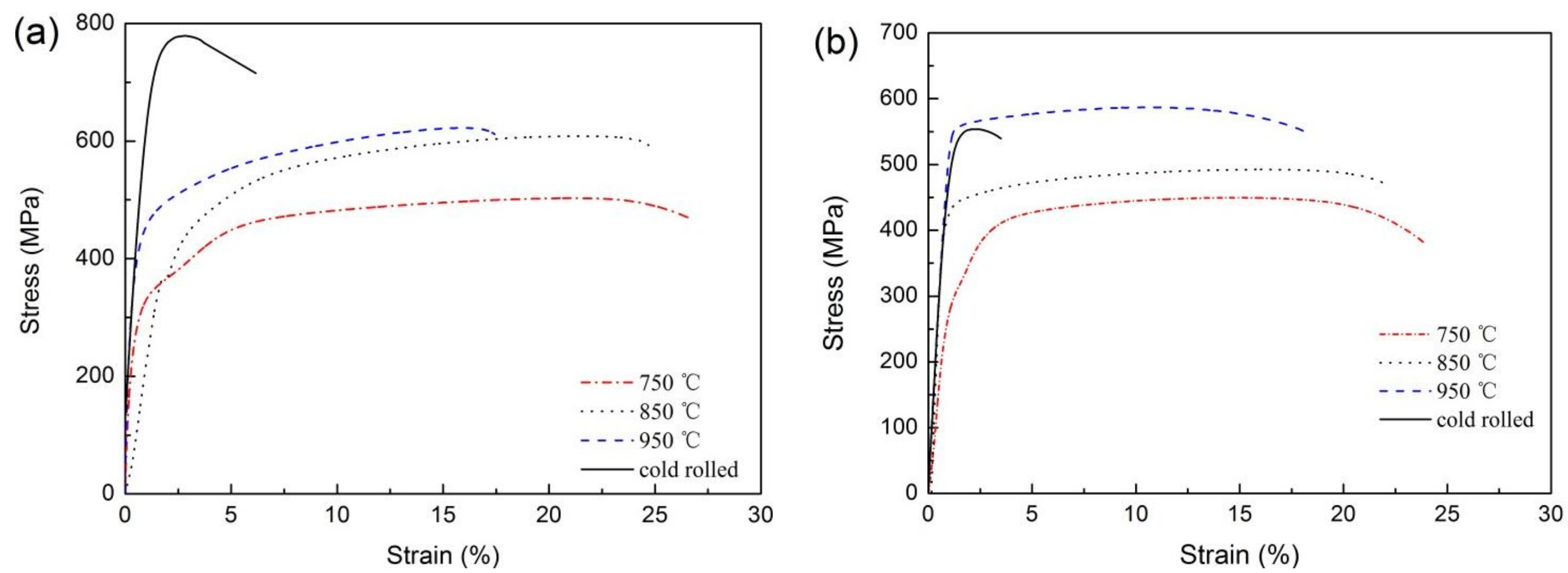

Fig. 3 Tensile strain-stress curves of Ti-Nb alloys: (a) Ti-20Nb; (b) Ti-30Nb 

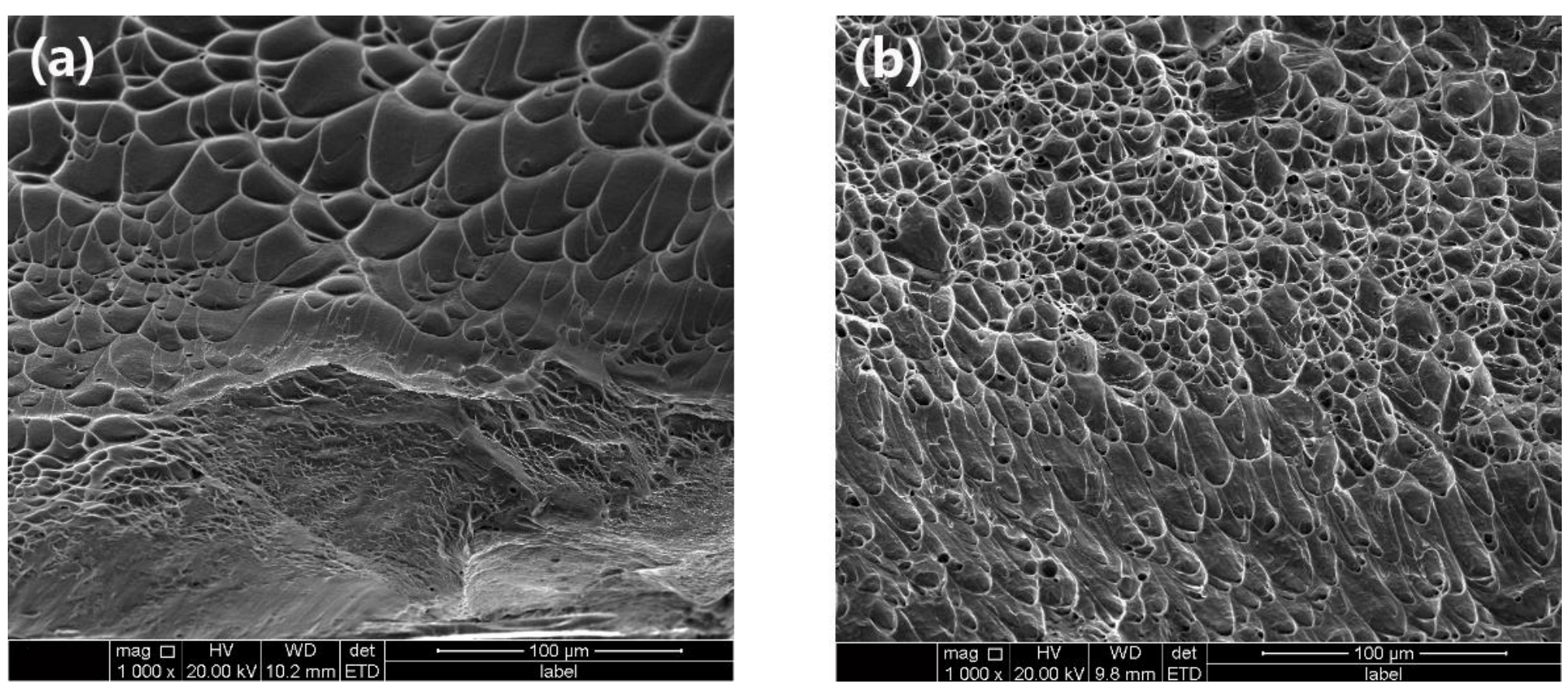

Fig. 4 Fracture surface of Ti-Nb alloys in solution treated conditions: (a)Ti-20Nb-850 ${ }^{\circ} \mathrm{C}$; (b)Ti-30Nb-850 ${ }^{\circ} \mathrm{C}$ 

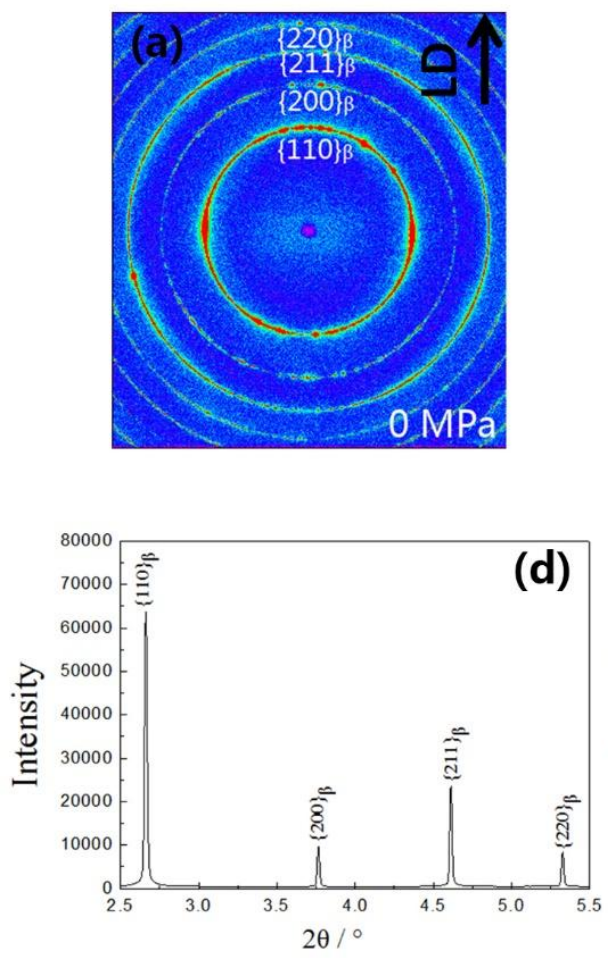
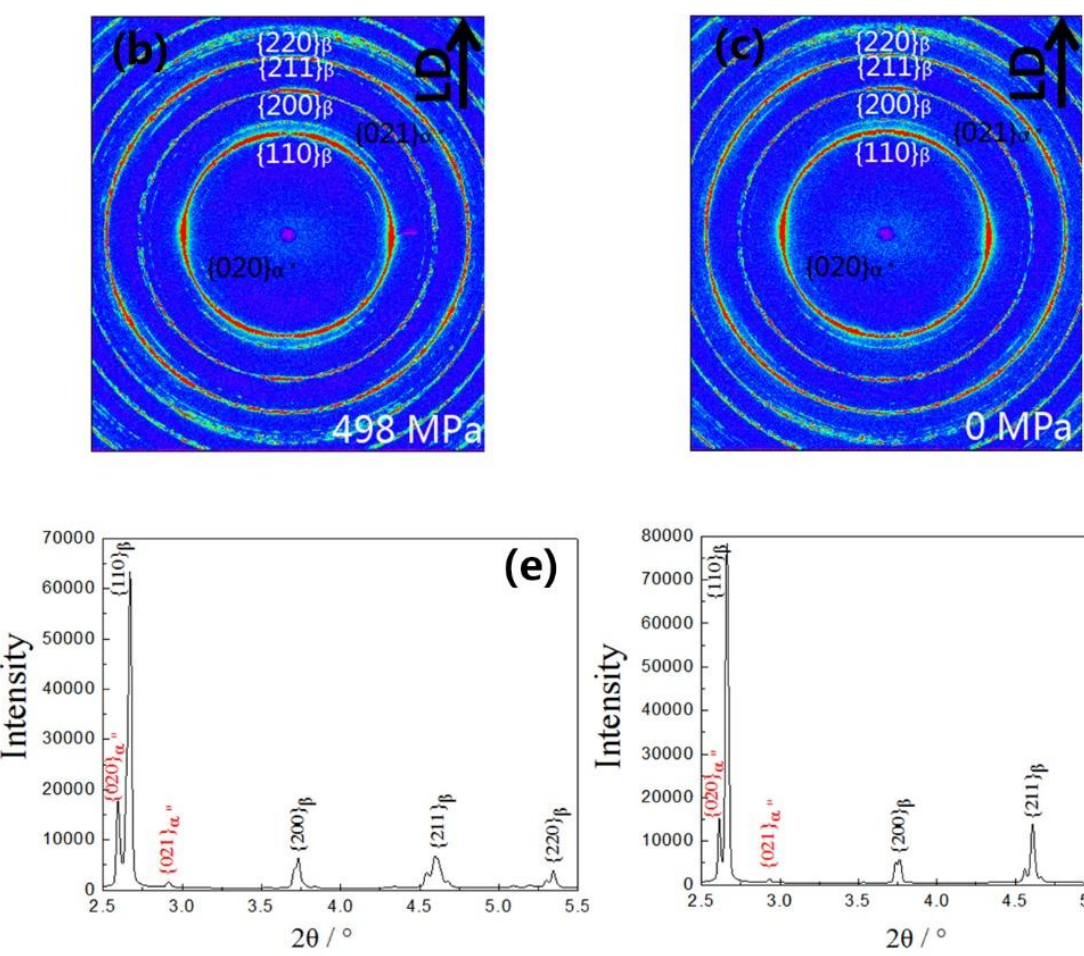

Fig. 5 Two-dimensional X-ray diffraction patterns of Ti-30Nb-850 during in-situ tension: (a) $0 \mathrm{MPa}$ (before loading), (b) $498 \mathrm{MPa}$ (at the maximum stress) and (c) $0 \mathrm{MPa}$ (after unloading) and one-dimensional patterns of the Ti-Nb sample corresponding to different deformation stages along LD: (d) $0 \mathrm{MPa}$ (before loading), (e) $498 \mathrm{MPa}$ (at the maximum stress) and (f) $0 \mathrm{MPa}$ (after unloading). 
(a)

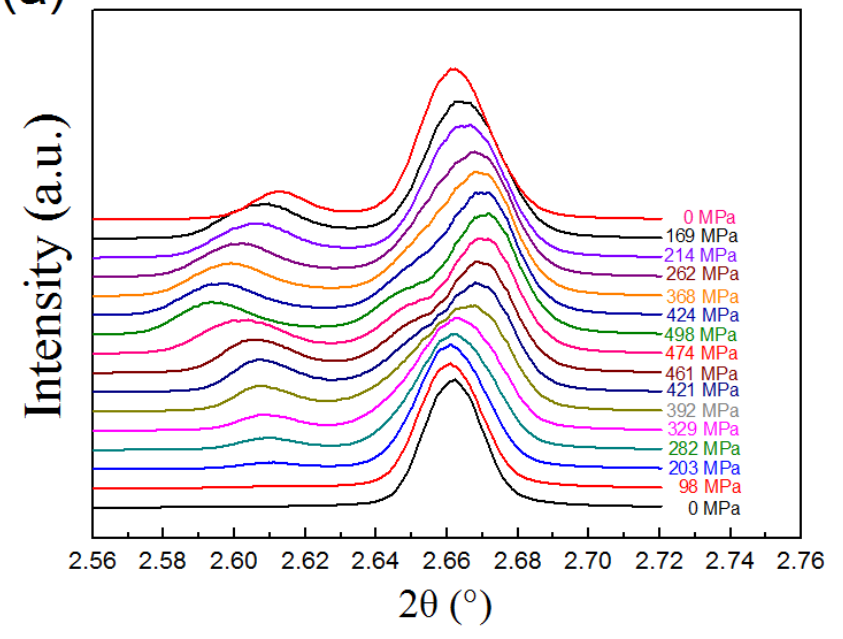

(b)

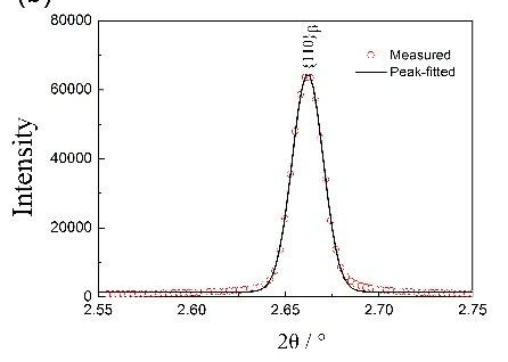

(c)

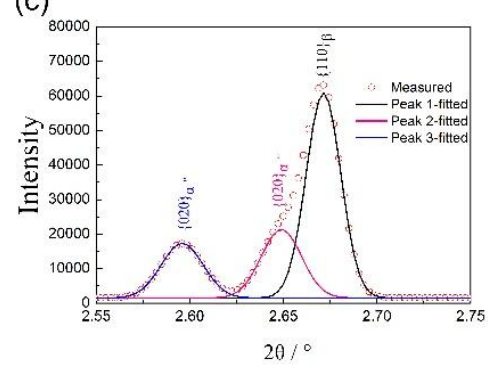

(d)

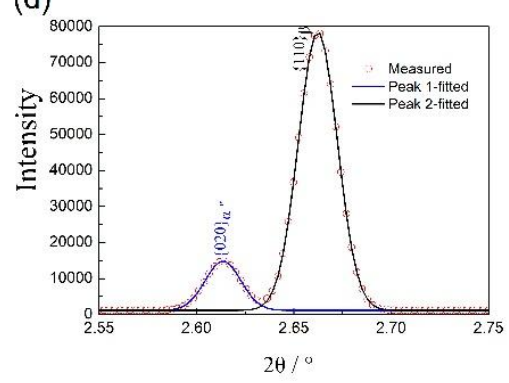

Fig. 6 (a) One-dimensional diffraction patterns of the Ti-Nb sample during in-situ deformation at different applied stressed. The highlighted diffraction profile near $\{110\}_{\beta}$ peak at (b) $0 \mathrm{MPa}$ (before loading), (c) $498 \mathrm{MPa}$ (at the maximum stress) and (d) $0 \mathrm{MPa}$ (after unloading). 
(a)
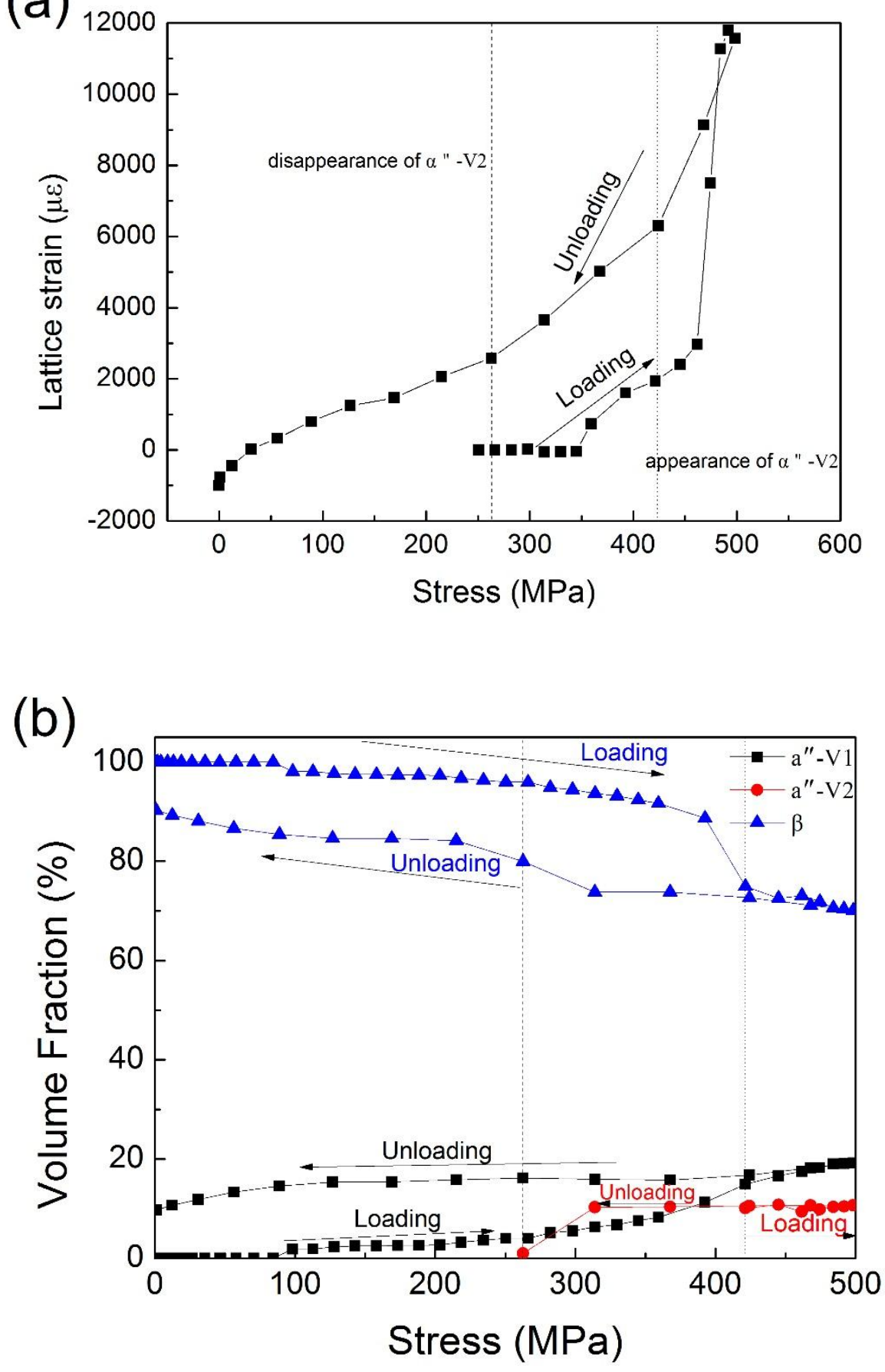

Fig. 7 (a) Lattice strain evolution during in-situ tension for $\{020\}_{\alpha^{\prime \prime}}(\mathrm{LD})$ and (b) evolution of volume fraction of $\beta, \alpha^{\prime \prime}$-V1 and $\alpha^{\prime \prime}-\mathrm{V} 1$ with the macroscopic stress during in-situ deformation 
Table 1 Lattice parameters of phases in Ti-20Nb and Ti-30Nb alloys

\begin{tabular}{lcccc}
\hline Samples & $\mathrm{a}_{\beta}(\AA)$ & $\mathrm{a}_{\alpha^{\prime \prime}}(\AA)$ & $\mathrm{b}_{\alpha^{\prime \prime}}(\AA)$ & $\mathrm{c}_{\alpha^{\prime \prime}}(\AA)$ \\
\hline Ti-20Nb-CR & 3.2714 & 3.0805 & 4.8300 & 4.7256 \\
Ti-20Nb-750 ${ }^{\circ} \mathrm{C}$ & 3.2709 & 3.1436 & 4.8629 & 4.6418 \\
Ti-20Nb-850 ${ }^{\circ} \mathrm{C}$ & 3.2707 & 3.1061 & 4.8831 & 4.6679 \\
Ti-20Nb-950 ${ }^{\circ} \mathrm{C}$ & 3.2704 & 3.0931 & 4.8775 & 4.6621 \\
Ti-30Nb-CR & 3.2901 & - & - & - \\
Ti-30Nb-750 ${ }^{\circ} \mathrm{C}$ & 3.2875 & - & - & - \\
Ti-30Nb-850 ${ }^{\circ} \mathrm{C}$ & 3.2862 & - & - & - \\
Ti-30Nb-950 ${ }^{\circ} \mathrm{C}$ & 3.2838 & - & - & - \\
\hline
\end{tabular}


Table 2 Tensile properties of Ti-Nb alloys

\begin{tabular}{lcccc}
\hline \multicolumn{1}{c}{ Samples } & $\mathrm{E}(\mathrm{GPa})$ & $\sigma_{0.2}(\mathrm{MPa})$ & $\sigma_{\mathrm{b}}(\mathrm{MPa})$ & $\delta(\%)$ \\
\hline Ti-20Nb-CR & 118 & 627 & 779 & 2.9 \\
Ti-20Nb-750 ${ }^{\circ} \mathrm{C}$ & 88 & 270 & 503 & 25.8 \\
Ti-20Nb-850 ${ }^{\circ} \mathrm{C}$ & 49 & 364 & 608 & 24.9 \\
Ti-20Nb-950 ${ }^{\circ} \mathrm{C}$ & 116 & 390 & 623 & 16.9 \\
Ti-30Nb-CR & 67 & 484 & 561 & 5.7 \\
Ti-30Nb-750 ${ }^{\circ} \mathrm{C}$ & 47 & 273 & 449 & 21.4 \\
Ti-30Nb-850 ${ }^{\circ} \mathrm{C}$ & 45 & 411 & 493 & 21.1 \\
Ti-30Nb-950 ${ }^{\circ} \mathrm{C}$ & 57 & 541 & 587 & 17.1 \\
\hline
\end{tabular}

